\title{
Assessment of PD-L1 expression in patients with neuroblastoma and renal tumors
}

\author{
Seher Şener ${ }^{1 \oplus}$, Aylar Poyraz ${ }^{2 \oplus}$, Arzu Okur ${ }^{1 \oplus}$, Faruk Güçlü Pınarl1 ${ }^{1 \oplus,}$ \\ Ceyda Karadeniz ${ }^{1 \oplus}$ \\ Departments of ${ }^{1}$ Pediatric Oncology and ${ }^{2}$ Pathology, Gazi University Faculty of Medicine Hospital, Ankara, Turkey.
}

\begin{abstract}
Background. Programmed death 1 (PD-1) is a co-receptor which is located at the surface of cells like natural killer, monocytes, T and B cells. It has two ligands including programmed death ligand-1 (PD-L1) and ligand-2 (PD-L2). T cell functions are inhibited by activation of PD-1/PD-L1 pathway and this pathway is used by viruses and some tumor cells in order to escape from immune eradication. In our study we evaluated PD-L1 expression in the tissue specimens of patients with Wilms tumor, neuroblastoma and other renal tumors.
\end{abstract}

Methods. Totally 60 patients who were followed up at Gazi University Hospital with the diagnosis of neuroblastoma, Wilms tumor and other renal tumors were included. PD-L1 expression was examined in tumor samples of the patients.

Results. Positive staining with PD-L1 was detected only in two male patients. Both of them had neuroblastoma and advanced stage disease. None of the patients with Wilms tumor and other renal tumors had positive PD-L1 staining.

Conclusions. Unlike adult tumors, PD-L1 expression is not common in childhood tumors due to differences in immune system between children and adults. Further studies are needed to establish the importance and effects of PD-1/PD-L1 pathway in pediatric tumors.

Key words: programmed death-1, programmed death ligand-1, programmed death ligand-2, neuroblastoma, childhood renal tumors.

The Programmed death 1 (PD-1) receptor is located on the surface of natural killer (NK) cells, activated monocytes and some subgroups of dendritic cells as well as T cells and B cells. ${ }^{1}$ The PD-1 receptor has two ligands; "programmed death ligand 1 (PD-L1)" and "programmed death ligand 2 (PD-L2)". 2,3 Although PD-L1 expression is easily inducible in many different cell types, PD-L2 expression is limited to only antigen presenting cells. This finding suggests that PD-L1 may play a more general and more specific role in inhibiting $\mathrm{T}$ cell activation than PD-L2. The PD-1/PD-L1 pathway is used

\footnotetext{
$凶$ Seher Şener

kzl_seher@hotmail.com
}

Received 16th October 2020, revised 9th February 2021, accepted 7th March 2021. by some tumors and viruses to escape from immune eradication. Activation of PD-1/PD-L1 pathway leads inhibition of $\mathrm{T}$ cell functions in secondary lymphoid tissues. ${ }^{4}$

PD-L1 is a transmembrane surface glycoprotein expressed in many solid tumors. There are many studies about the role of PD-1/PD-L1 pathway in adult malignancies and PD-1 and PD-L1 inhibiting agents have an important place in the treatment of adult cancers. However, the number of studies on the expression of PD-L1 in childhood solid tumors like neuroblastoma (NB), Wilms tumor (WT) and other primary renal tumors are not enough and results of these studies are conflicting. PD-1 and PD-L1 inhibiting agents have also begun to be used in the treatment of some childhood cancers. ${ }^{5,6}$ Although PD-L1 blockademay bean appropriate 
treatment option especially in patients with unfavorable prognosis and refractory disease despite treatment with current therapies, there is insufficient data about the effects of PD-L1 blockade on immune functions in pediatric patients. ${ }^{7}$ Therefore, we aimed to investigate whether PD-L1 expression is increased in tumor tissues of NB, WT and other primary renal tumors [congenital mesoblastic nephroma $(\mathrm{CMN})$, rhabdoid tumor of the kidney (RTK), renal cell carcinoma (RCC), clear cell sarcoma (CCS)] and whether there is a relationship between the degree of PD-L1 expression and the stage and prognosis of diseases.

\section{Material and Methods}

A total of 60 patients under 18 years of age who were followed between 2006 and 2017 with the diagnoses of NB $(n=34)$, WT $(n=17)$ and other renal tumors $(n=9)$ at Department of Pediatric Oncology in Gazi University Faculty of Medicine were included in the study. We evaluated NB patients' characteristics including age, Turkish Pediatric Oncology Group (TPOG) risk group of tumor, Shimada histological classification, metastasis status, mitosis karyorrhexis index (MKI), neuron-specific enolase (NSE), vanillylmandelic acid (VMA)/homovanillic acid (HVA) ratio, ferritin and lactate dehydrogenase (LDH) level, maximum standardized uptake value (SUVmax) on PET/CT, MYCN gene amplification and other mutations. ${ }^{8,9}$ We also assessed prognostic factors in patients with WT such as stage, tumor weight, tumor histology (presence of anaplasia) and metastasis status. In addition, stage and metastasis status in patients with other primary renal tumors were evaluated. Overall survival (OS) and event-free survival (EFS) were estimated in all patients. The time from diagnosis to death was defined as OS, and the time from diagnosis to relapse or treatment failure was defined as EFS.

PD-L1 expression was evaluated in tumor tissues of all cases. Hematoxylin \& eosin stained slides of each case were examined and two separate slides of each case with dense tumor and the least necrotic ones were selected. Immunohistochemical staining of PD-L1 was performed on slides prepared by modified tissue microarray method. Formalin fixed sections ( $4 \mu \mathrm{m}$ thickness) were exposed to anti-PD-L1 (clone SP142 rabbit monoclonal primary antibody) antibody and they were stained via OptiView DAB IHC Detection Set and OptiView Amplification kit on VENTANA BenchMark ultra instrument. Tonsil tissue was used as positive control. PD-L1 stained slides were evaluated by two different observers who were unaware of the clinical features of the cases. PD-L1 expression was evaluated in detail, assuming significant membranous staining in tumor cells, similar to previous studies. Staining of the tumor cells were scored according to percentage of stained cells as shown in Table I. ${ }^{6,10}$ Tumor cells scored $+1,+2$ and +3 were considered positive for PD-L1 expression.

The study protocol was approved by the Institutional Ethics Committee of Gazi University Faculty of Medicine with the decision number 11/2017-546 of December 01, 2017. This study was supported by Gazi University Scientific Research Projects Unit. Informed consent was taken from all families.

\section{Statistical Analysis}

Statistical analysis was performed using Statistical Package for Social Sciences (SPSS) for Windows 20 (IBM SPSS Inc., Chicago, IL). Continuous variables were summarized as mean \pm standard deviation (SD) while discrete data were presented as median and minimummaximum values. Survival analysis was performed using Kaplan-Meier curves and logrank tests.

Table I. Assessment of staining score and percentage of stained tumor cells.

\begin{tabular}{lc}
\hline $\begin{array}{l}\text { Staining score in tumor } \\
\text { cells }\end{array}$ & $\begin{array}{c}\text { Percentage of stained } \\
\text { tumor cells }(\%)\end{array}$ \\
\hline 0 & $<1$ \\
+1 & $\geq 1$ and $<5$ \\
+2 & $\geq 5$ and $<50$ \\
+3 & $\geq 50$ \\
\hline
\end{tabular}




\section{Results}

A total of 60 cases enrolled in the study. Mean age was $41.6 \pm 38.8$ months and $53.3 \%(n=32)$ of the patients were male. Most of the patients were diagnosed NB $(n=34)$ while other patients were diagnosed WT $(n=17)$ and other renal tumors $(\mathrm{n}=9)$. The median follow-up was 79 (6143) months.

\section{Patients with neuroblastoma}

Thirty-four patients with NB were included in the study. Mean age was $30.7 \pm 27.9$ months and 20 patients (58.8\%) were male. The demographic characteristics of the cases are showed in Table II. Mean OS was $110.1 \pm 10.1$ months and EFS was $92.8 \pm 11.6$ months (Fig. 1).

\section{Patients with Wilms Tumor}

Seventeen patients with WT were included in the study. Mean age was $42.5 \pm 39.7$ months and $6(35.2 \%)$ patients were male. The demographic characteristics of the cases are discussed in detail in Table III. Mean OS was $104.2 \pm 9.3$ months and EFS was $103.0 \pm 8.8$ months (Fig. 2).

\section{Patients with Other Renal Tumors}

Four patients with RCC were included in the study. The mean age of the patients with RCC was $138.6 \pm 59.4$ months and three of them were male. Two patients of them had stage II and others had stage IV disease. Tumor tissues of three patients with RCC were obtained before chemotherapy. Two patients of them had metastatic disease and they died at $4^{\text {th }}$ and $21^{\text {th }}$ months of treatment. Another two patients with RCC are still alive with complete remission for 103 months.

There were two patients with CMN. Ages of the patients with $\mathrm{CMN}$ were 10 and 20 months and one of them was female. Tumor tissues were obtained before chemotherapy in both of the patients with $\mathrm{CMN}$ and they did not have metastatic disease and no relapse or death was observed during the follow-up period. They are still alive with remission for 56 months.
Table II. Characteristics of patients with neuroblastoma.

\begin{tabular}{|c|c|}
\hline Number of patients (n) & 34 \\
\hline Age (months), mean $( \pm \mathrm{SD})$ & $30.7 \pm 27.9$ \\
\hline$<18$ months & $15(44 \%)$ \\
\hline$\geq 18$ months & $19(56 \%)$ \\
\hline Sex, male, n (\%) & $20(58.8 \%)$ \\
\hline \multicolumn{2}{|l|}{ Stage } \\
\hline I & $3(\% 8.8)$ \\
\hline II & $1(\% 2.9)$ \\
\hline III & $9(\% 26.5)$ \\
\hline IV & $21(\% 61.8)$ \\
\hline \multicolumn{2}{|l|}{ Biopsy } \\
\hline Before chemotherapy & $32(94 \%)$ \\
\hline After chemotherapy & $2(6 \%)$ \\
\hline \multicolumn{2}{|l|}{ SUVmax } \\
\hline$<2.5$ & $6(23.1 \%)$ \\
\hline$\geq 2.5$ & $20(76.9 \%)$ \\
\hline Metastasis & $20(59 \%)$ \\
\hline \multicolumn{2}{|l|}{ Metastasis site } \\
\hline Bone marrow & $13(28.9 \%)$ \\
\hline Bone & $10(22.3 \%)$ \\
\hline Liver & $6(13.4 \%)$ \\
\hline Lymph node & $5(11.1 \%)$ \\
\hline Others & $11(32.3 \%)$ \\
\hline \multicolumn{2}{|l|}{ TPOG risk group } \\
\hline Low risk & $5(14.7)$ \\
\hline Intermediate risk & $13(38.2 \%)$ \\
\hline High risk & $16(47.1 \%)$ \\
\hline \multicolumn{2}{|l|}{ Shimada classification } \\
\hline Favorable & $26(76.5 \%)$ \\
\hline Unfavorable & $8(23.5 \%)$ \\
\hline \multicolumn{2}{|l|}{ MKI } \\
\hline$<2 \%$ & $21(61.8 \%)$ \\
\hline $2-4 \%$ & $7(20.6 \%)$ \\
\hline$>4 \%$ & $6(17.6 \%)$ \\
\hline \multicolumn{2}{|l|}{ Primary region } \\
\hline Abdomen & $26(76.5 \%)$ \\
\hline Posterior mediastinum & $6(17.6 \%)$ \\
\hline Pelvic & $2(5.8 \%)$ \\
\hline NSE $>100 \mathrm{ng} / \mathrm{mL}$ & $30(88 \%)$ \\
\hline Ferritin $>150 \mathrm{ng} / \mathrm{mL}$ & $11(32.4 \%)$ \\
\hline VMA/HVA ratio >1 & $27(79.4 \%)$ \\
\hline $\mathrm{LDH}>1500 \mathrm{U} / \mathrm{L}$ & $12(35.3 \%)$ \\
\hline \multicolumn{2}{|l|}{ Mutations } \\
\hline MYCN gene amplification & $8(23.5 \%)$ \\
\hline $1 \mathrm{p}$ deletion & $18(75 \%)$ \\
\hline 11q deletion & $9(37.5 \%)$ \\
\hline Gain of $17 q$ & $17(70.8 \%)$ \\
\hline Hyperdiploid & $8(33.3 \%)$ \\
\hline Relapse/resistant disease & $9(26.4 \%)$ \\
\hline Death & $7(20.6 \%)$ \\
\hline
\end{tabular}

SUVmax: maximum standardized uptake value, TPOG: Turkish Pediatric Oncology Group, MKI: mitosis karyorrhexis index, NSE: neuron-specific enolase, HVA: homovanillic acid, VMA: vanillylmandelic acid, LDH: lactate dehydrogenase. 

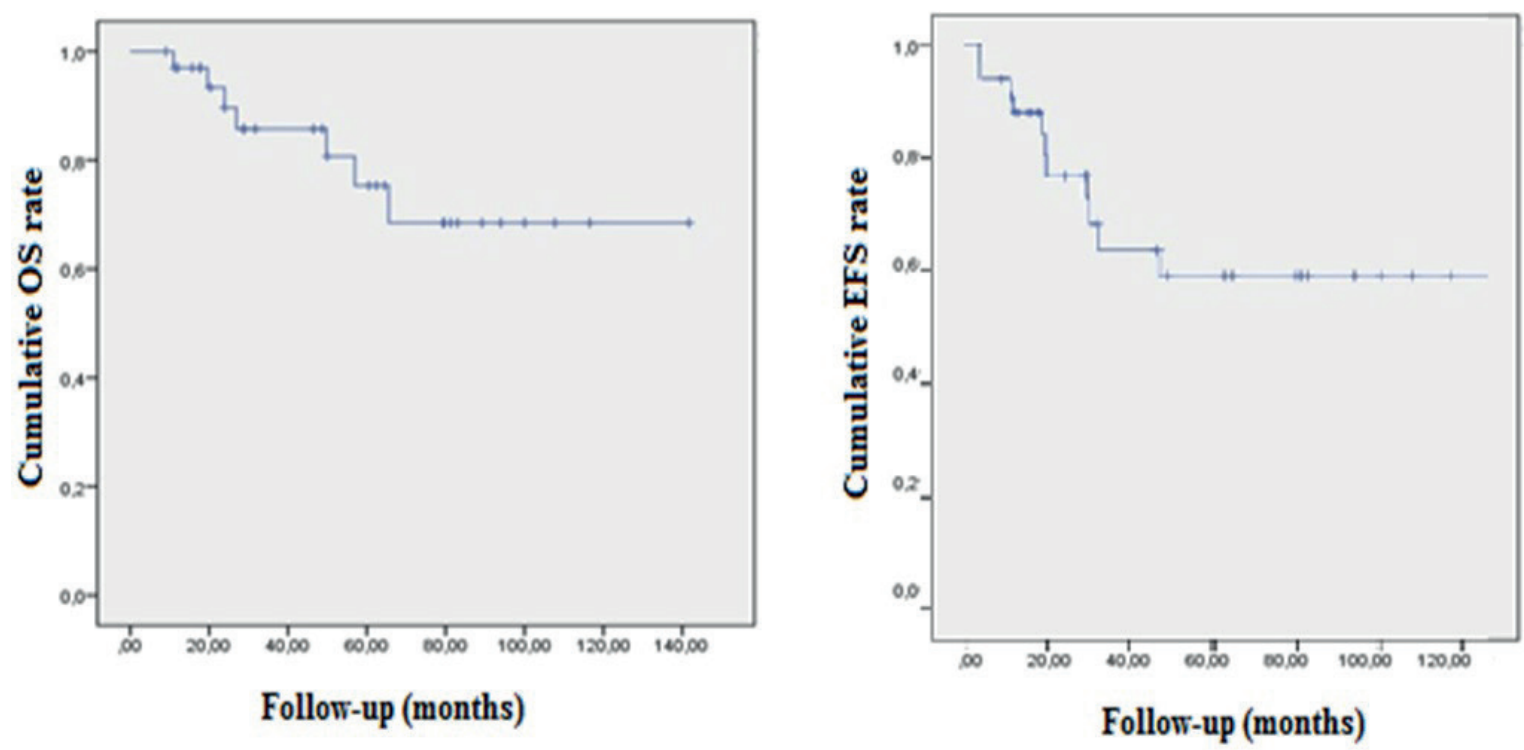

Fig. 1. OS and EFS curve of patients with neuroblastoma.
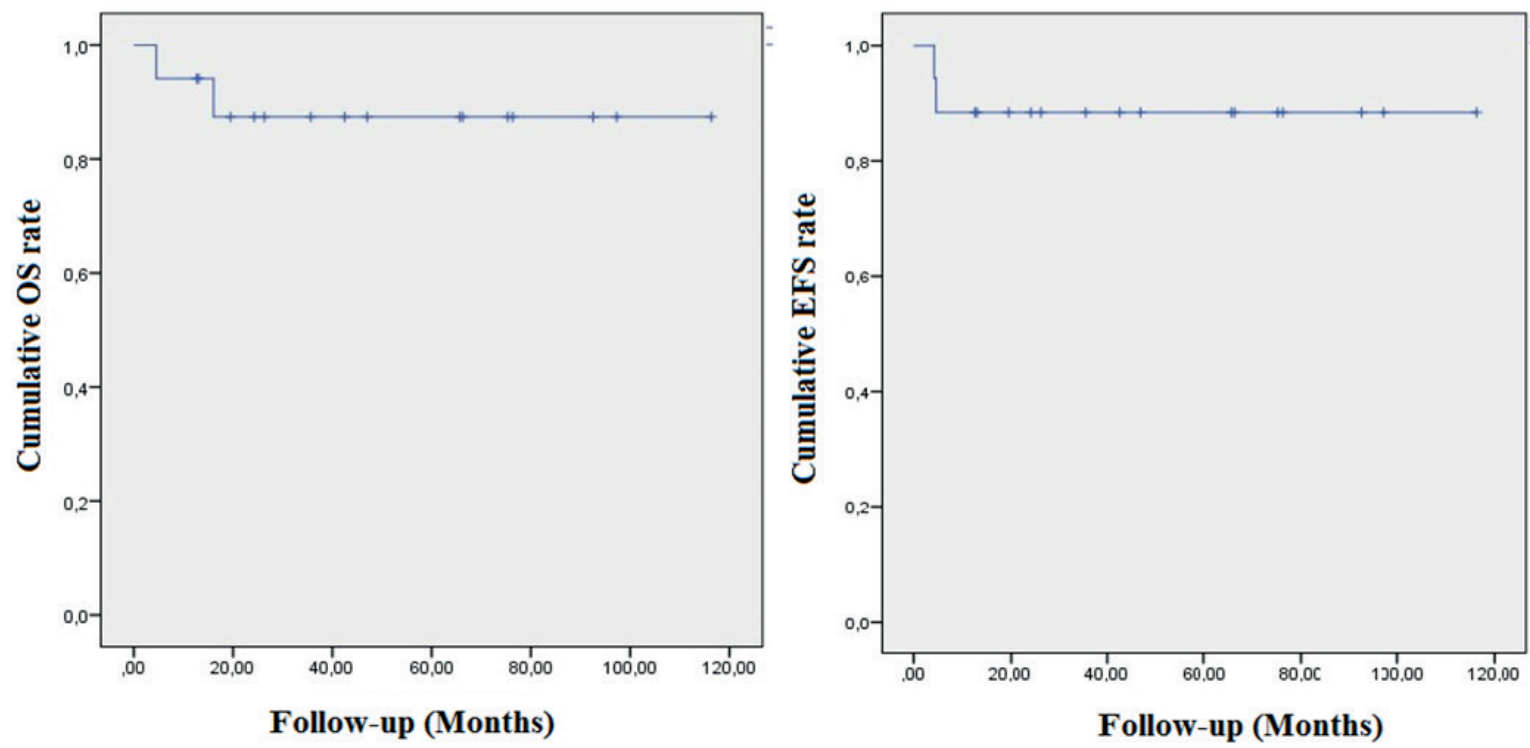

Fig. 2. OS and EFS curve of patients with Wilms tumor.

There were two patients with RTK. Ages of the patients with RTK were 10 and 102 months and one of them was male. Tumor specimen was obtained before chemotherapy in one patient and after chemotherapy in the other case. Both of the patients with RTK had metastatic disease and they died at $7^{\text {th }}$ and $11^{\text {th }}$ months of treatment.

The only patient with CCS diagnosis was male and he was 30 months of age. His tumor tissue was obtained after chemotherapy and he did not have metastatic disease. No relapse occurred and he is alive with remission for 83 months.

PD-L1 Expression in Patients with neuroblastoma

PD-L1 positive staining (membranous staining of $1 \%$ or more) (Fig. 3) was detected in two of 34 patients with NB (Table IV). In one patient with NB, PD-L1 staining was observed below $1 \%$ and 
it was accepted negative for PD-L1 expression. Table V shows detailed clinical features of PDL1 positive staining cases.

Table III. Characteristics of patients with Wilms tumor.

\begin{tabular}{lc}
\hline Number of patients $(\mathrm{n})$ & 17 \\
\hline Age (months), mean $( \pm$ SD) & $42.5 \pm 39.7$ \\
Sex, male, $\mathrm{n}(\%)$ & $6(35.2 \%)$ \\
Stage & \\
$\quad$ I & $3(17.6 \%)$ \\
II & $3(17.6 \%)$ \\
III & $5(29.4 \%)$ \\
IV & $6(35.4 \%)$ \\
Biopsy & \\
$\quad$ Before chemotherapy & $6(35.3 \%)$ \\
$\quad$ After chemotherapy & $11(64.7 \%)$ \\
Metastasis & $5(29.4 \%)$ \\
Metastasis site & \\
$\quad$ Lung & $5(100 \%)$ \\
Pathology & \\
$\quad$ Favorable & $15(88.2 \%)$ \\
$\quad$ Unfavorable/Anaplasia $(+)$ & $2(11.8 \%)$ \\
Tumor weight & \\
$\quad<550$ gr & $11(64.7 \%)$ \\
$\quad \geq 550$ gr & $6(35.3 \%)$ \\
Relapse/resistant disease & $1(5.9 \%)$ \\
Death & $2(11.8 \%)$ \\
\hline
\end{tabular}

\section{PD-L1 Expression in Renal Tumors}

None of the patients with WT, CMN, RTK, RCC and CCS had positive staining for PDL1. Therefore, the relationship between PD-L1 expression and prognostic factors, stages and prognosis of patients could not be evaluated in these group of patients.

\section{Discussion}

Significant advances occurred in targeted therapy thanks to the definition of various genetic mutations in childhood cancers. Immunotherapy which detects tumor cells as foreign bodies and activates the host immune response has become prominent in the treatment of some cancers, due to the strong relationship between tumor microenvironment and host immune system. Antibodies targeting the PD-1/ PD-L1 pathway which was developed to induce immune system against tumor cells might also increase patients' survival with less toxicity than conventional chemotherapeutic regimens. ${ }^{11}$ Therefore; the clinical importance of PD-L1 expression and its relationship with prognosis and treatment response should be highlighted in childhood cancers. So we evaluated PD-L1 expression in NB and childhood renal tumors.

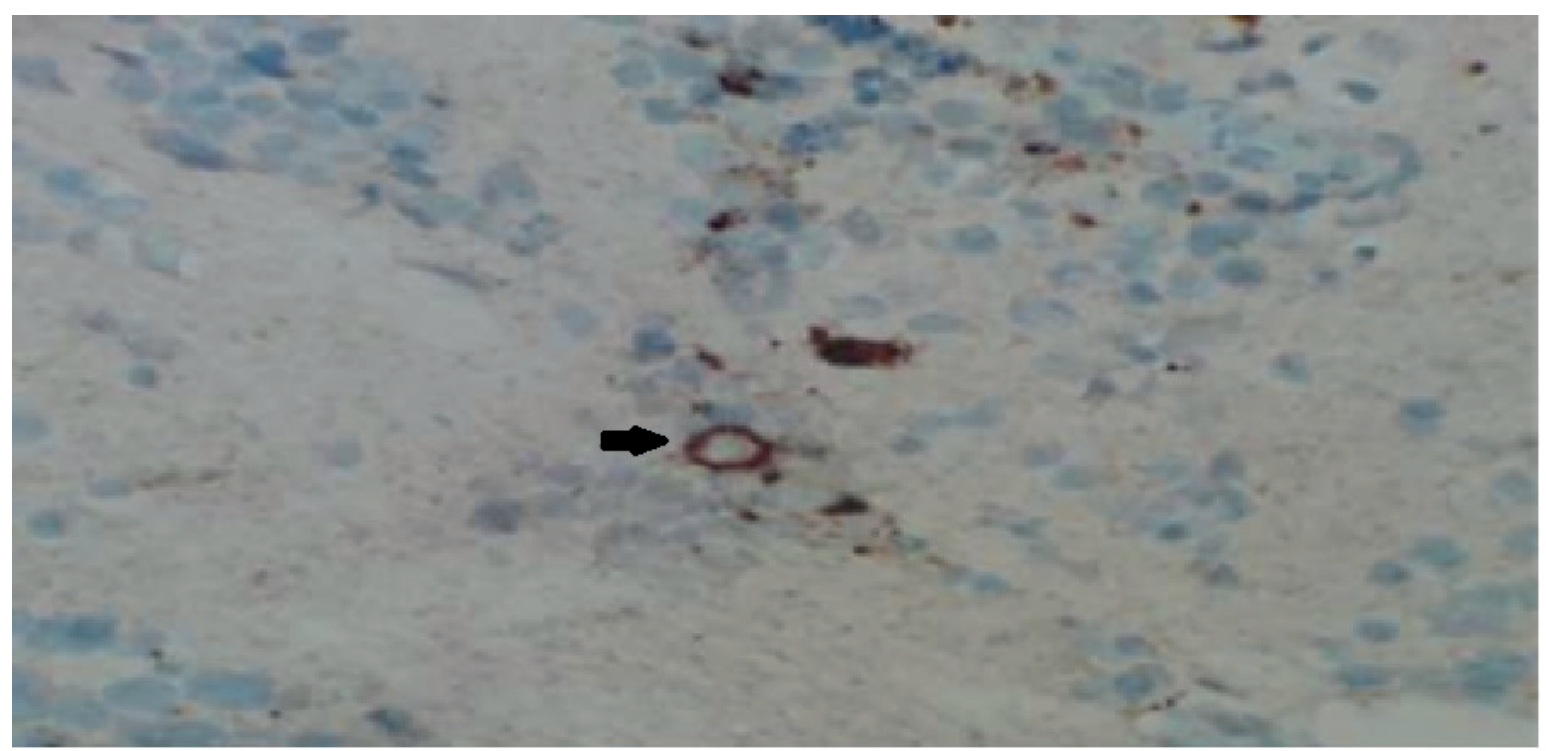

Fig. 3. PD-L1 staining between $1 \%$ and $5 \%$ of tumor cells in neuroblastoma (X100). 
Table IV. PD-L1 expression and clinicopathologic features in patients with neuroblastoma.

\begin{tabular}{|c|c|c|}
\hline & PD-L1 (-) & PD-L1 (+) \\
\hline \multicolumn{3}{|l|}{ Sex $(n=34)$} \\
\hline Female & $14(100 \%)$ & 0 \\
\hline Male & $18(90 \%)$ & $2(10 \%)$ \\
\hline \multicolumn{3}{|l|}{ Age (months) } \\
\hline$<18$ & $14(93.3 \%)$ & $1(6.7 \%)$ \\
\hline$\geq 18$ & $18(94.7 \%)$ & $1(5.3 \%)$ \\
\hline \multicolumn{3}{|l|}{ Stage } \\
\hline I, II, III, IVS & $13(100 \%)$ & 0 \\
\hline IV & $19(90.5 \%)$ & $2(9.5 \%)$ \\
\hline \multicolumn{3}{|l|}{ Biopsy } \\
\hline Before chemotherapy & $30(93.7 \%)$ & $2(6.3 \%)$ \\
\hline After chemotherapy & $2(100 \%)$ & 0 \\
\hline \multicolumn{3}{|l|}{ TPOG risk group } \\
\hline Low risk & $5(100 \%)$ & 0 \\
\hline Medium risk & $13(100 \%)$ & 0 \\
\hline High risk & $14(87.5 \%)$ & $2(12.5 \%)$ \\
\hline \multicolumn{3}{|l|}{ Shimada classification } \\
\hline Favorable & $26(100 \%)$ & 0 \\
\hline Unfavorable & $6(75 \%)$ & $2(25 \%)$ \\
\hline \multicolumn{3}{|l|}{ MKI } \\
\hline$<2 \%$ & $20(95.2 \%)$ & $1(4.8 \%)$ \\
\hline $2-4 \%$ & $7(100 \%)$ & 0 \\
\hline$>4 \%$ & $5(83.3 \%)$ & $1(16.7 \%)$ \\
\hline \multicolumn{3}{|l|}{ MYCN gene amplification } \\
\hline Negative & $24(92.3 \%)$ & $2(7.7 \%)$ \\
\hline Positive & $8(100 \%)$ & 0 \\
\hline
\end{tabular}

TPOG: Turkish Pediatric Oncology Group, MKI: mitosis karyorrhexis index.

In our study, positive PD-L1 expression was observed in only two of 34 cases with NB. Due to the small number of PD-L1 positive cases $(n=2)$, it was not suitable to perform statistical analysis and evaluate the relationship between PD-L1 expression and prognostic factors. Both of the PD-L1 positive cases were stage IV NB and high risk NB. Therefore; PD-L1 positivity was detected in $9.5 \%$ of the stage IV NB patients and in $12.5 \%$ of the high-risk NB cases. Both of the patients were within 8 cases with unfavorable prognosis according to Shimada classification (25\%) and they were within 26 cases with negative MYCN gene amplification
Table V. Demographic characteristics of two PD-L1 positive patients with neuroblastoma.

\begin{tabular}{|c|c|c|}
\hline & Case 1 & Case 2 \\
\hline Age (months) & 24 & 14 \\
\hline Sex & Male & Male \\
\hline Stage & IV & IV \\
\hline Biopsy & $\begin{array}{l}\text { Before } \\
\text { chemotherapy }\end{array}$ & $\begin{array}{l}\text { Before } \\
\text { chemotherapy }\end{array}$ \\
\hline SUVmax & $4.9(\uparrow)$ & $5.3(\uparrow)$ \\
\hline Primary region & $\begin{array}{l}\text { Posterior } \\
\text { mediastinum }\end{array}$ & Abdomen \\
\hline Metastasis & Yes & Yes \\
\hline Metastasis site & Bone marrow & $\begin{array}{l}\text { Bone, bone } \\
\text { marrow, lymph } \\
\text { node }\end{array}$ \\
\hline TPOG risk group & High risk & High risk \\
\hline $\begin{array}{l}\text { Shimada } \\
\text { classification }\end{array}$ & Unfavorable & Unfavorable \\
\hline MKI & $<2 \%(\downarrow)$ & $>4 \%(\uparrow)$ \\
\hline NSE & 159 ng/mL ( () & $187 \mathrm{ng} / \mathrm{mL}(\uparrow)$ \\
\hline VMA/HVA ratio & $1.2(\uparrow)$ & 0.8 \\
\hline Ferritin & $54 \mathrm{ng} / \mathrm{Ml}$ & $197 \mathrm{ng} / \mathrm{Ml}(\uparrow)$ \\
\hline $\mathrm{LDH}$ & $2300 \mathrm{U} / \mathrm{L}(\uparrow)$ & $1873 \mathrm{U} / \mathrm{L}(\uparrow)$ \\
\hline $\begin{array}{l}\text { MYCN gene } \\
\text { amplification }\end{array}$ & Negative & Negative \\
\hline Hyperdiploid & Not assessed & No \\
\hline 1p deletion & Not assessed & Positive \\
\hline 11q deletion & Not assessed & Negative \\
\hline Gain of $17 q$ & Not assessed & Negative \\
\hline $\begin{array}{l}\text { Relapse/resistant } \\
\text { disease }\end{array}$ & No & No \\
\hline Death & No & Yes \\
\hline Outcome & $\begin{array}{l}\text { Exitus (28 } \\
\text { months) }\end{array}$ & $\begin{array}{l}\text { Exitus }\left(11^{\text {th }}\right. \\
\text { months) }\end{array}$ \\
\hline
\end{tabular}

SUVmax: maximum standardized uptake value, TPOG: Turkish Pediatric Oncology Group, MKI: mitosis karyorrhexis index, NSE: neuron-specific enolase, HVA: homovanillic acid, VMA: vanillylmandelic acid, LDH: lactate dehydrogenase.

(7.7\%). The two cases with positive PD-L1 expression died at $11^{\text {th }}$ and $28^{\text {th }}$ months of follow-up. Although there are many studies in the literature about PD-L1 expression in adult cancers, there are limited and small studies about PD-L1 expression in pediatric malignant tumors. ${ }^{11-13}$ Moreover, contradictory results have been obtained in the current studies. ${ }^{14-19} \mathrm{It}$ 
is reported that PD-L1 expression is increased in patients with unfavorable prognosis according to Shimada classification and advanced stage tumors in NB. PD-L1 expression correlates with poor overall survival, but there are also studies showing no relationship between PDL1 expression and OS rate, tumor stage and histologic type. ${ }^{14-16,20}$ In the study published by Uehara et al. ${ }^{15}$ that includes 41 pediatric patients with NB high PD-L1 expression was detected in 5 patients $(12 \%)$ with advanced stage tumors, and PD-L1 expression was associated with poor OS. In another study including 43 patients with NB, positive PD-L1 expression was shown in 31 cases $(72 \%)$, and tumors with high PDL1 expression were found to have a better OS rates than those without expression. ${ }^{16}$ Majzner et al. ${ }^{20}$ expressed that positive PD-L1 expression was observed in 17 (14\%) of 118 patients with $\mathrm{NB}$ and no significant relationship was found between positive PD-L1 expression and OS rates at any stage or in any risk group. Dondero et al. $^{21}$ showed positive PD-L1 expression in $3(15.7 \%)$ of 19 patients with metastatic NB. There is only one study which compares the prognostic factors and PD-L1 expression in patients with NB in the literature. In this study by Saletta et al. ${ }^{19}$, positive PD-L1 expression was found in $48(19 \%)$ of 254 patients with NB. Positive PD-L1 expression was detected in 19 (20.9\%) of 91 cases with advanced stage NB and in $13(17.6 \%)$ of 74 cases with high risk NB. Positive PD-L1 expression was reported in 38 (31.9\%) of 119 cases with negative MYCN gene amplification and only two out of 34 patients with positive MYCN gene amplification (5.9\%). Positive PD-L1 expression was significantly higher in patients with negative MYCN gene amplification than counterparts with positive MYCN gene amplification, and there was no statistically significant relationship between PD-L1 expression and other prognostic factors. Additionally, unlike other studies, it has been observed that NB patients with positive PD-L1 expression have better OS rates. ${ }^{19}$

PD-L1 positive staining was not detected in any of the patients with WT, CMN, RTK, RCC and CSS in our study. In the literature; Routh et al. $^{14}$ found that positive PD-L1 expression was detected in $11(14 \%)$ of 81 patients with WT and PD-L1 expression has been reported to be a prognostic marker. In another study by Pinto et al. ${ }^{18}$, no positive PD-L1 expression was detected in any cases with WT as in our study.

In our study, chemotherapy was not administered to 44 cases (73.3\%) before biopsy. Thirty-two patients with NB (94\%) and 6 patients with WT (35.3\%) did not receive chemotherapy before biopsy, including the two patients with positive PD-L1 expression. Although biopsy samples of our patients were taken before chemotherapy $(73.3 \%)$, PD-L1 expression rate was found to be low. Other studies in the literature also included patients with biopsies taken both before and after chemotherapy as similar with our study. ${ }^{15,16,19,20}$ In the study by Saletta et al. ${ }^{19}$ reported that 64 patients with NB (34.4\%) received chemotherapy while 122 patients with NB (65.6\%) did not receive chemotherapy before biopsy. In the same study, PD-L1 expression positivity was found to be higher in patients who did not receive chemotherapy prior to biopsy [27.9\% (34/122)] than those who received chemotherapy $[15.6 \%$ $(10 / 64)]$.

Variations in PD-L1 expression rates in studies may also be associated with heterogeneity of the patient population and differences in the use of different scoring systems, antibody staining kits, staining procedures and antigen uptake techniques. For example, while evaluating PD-L1 staining positivity in tumor tissue, the median $\mathrm{H}$-score was used as a cutoff value in some studies; while the median value of the staining percentage of $5 \%$ and above was considered as the cut-off value in other studies. ${ }^{14-17}$ In our study, positive PDL1 expression was defined as the presence of $\geq 1 \%$ staining in tumor cells. In previous studies, staining in $\geq 1 \%$ of tumor cells were also accepted as positive for expression of cytokines, IFN- $\Upsilon$ and other immune markers. ${ }^{6,19,22-24}$ We preferred the most commonly used scoring system; however, different results might have been attained with separate scoring systems. 
The use of different antibodies (recombinant/polyclonal antibodies) in the immunohistochemical evaluation of PD-L1 expression in the studies may also play an important role in conflicting results. Different clone anti PD-L1 antibodies may lead to different results in the same tumor. ${ }^{25}$ Majzner et al. ${ }^{20}$ used clone 28-8 as PD-L1 antibody in their study while clone $5 \mathrm{H} 1$ was used as the PD-L1 antibody in another study published by Routh et al. $^{14}$ in patients with WT. The anti-PD-L1 antibody in these studies is different from the clone (SP 142) which we used in our study. However, a lower rate of response to tumorassociated antigens may occur in children, since burden of mutations is low but immunogenicity is higher in childhood cancers than adult counterparts. Therefore, PD-L1 expression in childhood tumors is lower than in adult cases in the literature. ${ }^{26}$

Modified tissue microarray method has been used the most in the literature for evaluating PD-L1 expression in childhood tumors as in our study. ${ }^{19,20}$ When PD-L1 expression is evaluated in sections using modified tissue microarray method, it is observed that PD-L1 shows a very heterogeneous distribution within the tumor. Hence, immunohistochemical examination with modified tissue microarray method may cause false negativity in terms of PD-L1 expression. Therefore, it is more appropriate to use whole tissue sections in the evaluation of PD-L1 expression. However; complete tissue sections can be obtained in prospective studies.

The first limitation of our study is the small number of cases and retrospective design. Some cases could not be included in the study because we couldn't reach the tissue specimens of the patients diagnosed before 2006 and some of the samples were very small and insufficient to evaluate PD-L1 expression. In the beginning, we had aimed to evaluate the relationship between PD-L1 expression and prognostic factors but due to the small number of PD-L1 positive cases, statistical analysis could not be performed.
To conclude, although PD-L1 positivity rate is higher in adult tumors and is often associated with advanced stage disease with poor prognosis, it is very low in childhood tumors. This situation may be due to differences in the pathogenesis of childhood and adult tumors. However, prospective studies with larger populations are needed to clarify this issue.

\section{Acknowledgment}

This research did not receive any specific grant from funding agencies in the public, commercial, or non-profit sectors.

\section{Author contribution}

The authors confirm contribution to the paper as follows: study conception and design: SŞ, $\mathrm{AP}, \mathrm{AO}, \mathrm{FGP}, \mathrm{CK}$; data collection: SŞ; analysis and interpretation of results: SS, AP, CK; draft manuscript preparation: SŞ, CK. All authors reviewed the results and approved the final version of the manuscript.

\section{Ethical approval}

The study protocol was approved by the Institutional Ethics Committee of Gazi University Faculty of Medicine with the decision number 11/2017-546 of December 01, 2017.

\section{Source of funding}

No financial relationship.

\section{Conflict of interest}

All the authors declare no conflict of interest.

\section{REFERENCES}

1. Keir M, Butte MJ, Freeman GJ, Sharpe AH. PD-1 and its ligands in tolerance and immunity. Ann Rev Immunol 2008; 26: 677-704.

2. Latchman $Y$, Wood C, Chernova T, et al. PD-L2 is a second ligand for PD-1 and inhibits T cell activation. Nat Immunol 2001; 2: 261-268. 
3. Tseng S, Otsuji M, Gorski K, et al. B7-DC, a new dendritic cell molecule with potent costimulatory properties for T cells. J Exp Med 2001; 193: 839-845.

4. Iwai $\mathrm{Y}$, Ishida M, Tanaka $\mathrm{Y}$, Okazaki T, Honjo T, Minato N. Involvement of PD-L1 on tumor cells in the escape from host immune system and tumor immunotherapy by PD-L1 blockade. Proc Natl Acad Sci USA 2002; 99: 12293-12297.

5. Topalian SL, Hodi FS, Brahmer JR, et al. Safety, activity, and immune correlates of anti-PD-1 antibody in cancer. N Engl J Med 2012; 366: 24432454.

6. Herbst RS, Soria JS, Kowanetz M, et al. Predictive correlates of response to the anti-PD-L1 antibody MPDL3280A in cancer patients. Nature 2014; 515: 563-567.

7. van Dam LS, de Zwart VM, Meyer-Wentrup FA. The role of programmed cell death-1 (PD-1) and its ligands in pediatric cancer. Pediatr Blood Cancer 2014; 62: 190-197.

8. Aksoylar S, Varan A, Vergin C, et al. Treatment of high-risk neuroblastoma: National protocol results of the Turkish Pediatric Oncology Group. J Can Res Ther 2017; 13: 284-290.

9. Shimada H, Ambros IM, Dehner LP, et al. The International Neuroblastoma Pathology Classification (the Shimada system). Cancer 1999; 86: 364-372.

10. Bertolini G, Bergamaschi L, Ferrari A, et al. PD-L1 assessment in pediatric rhabdomyosarcoma: a pilot study. BMC Cancer 2018; 18: 652.

11. Sznol M, Chen L. Antagonist antibodies to PD-1 and B7-H1 (PD-L1) in the treatment of advanced human cancer. Clin Cancer Res 2013; 19: 1021-1034.

12. Afreen S, Dermine S. The immunoinhibitory B7-H1 molecule as a potential target in cancer: killing many birds with one stone. Hematol Oncol Stem Cell Ther 2014; 7: 1-17.

13. Ohigashi Y, Sho M, Yamada Y, et al. Clinical significance of programmed death-1 ligand-1 and programmed death-1 ligand-2 expression in human esophageal cancer. Clin Cancer Res 2005; 11: 29472953.

14. Routh JC, Ashley RA, Sebo TJ, et al. B7-H1 expression in Wilms tumor: correlation with tumor biology and diseaser currence. J Urol 2008; 179: 1954-1960.

15. Uehara S, Nakahata K, Kawatsu M, et al. The PD-L1 expression increases after consecutive multimodal therapeies in neuroblastoma. Pediatr Blood Cancer 2015; 62: S334.
16. Chowdhury F, Dunn S, Mitchell S, Mellows T, Ashton-Key M, Gray JC. PD-L1 and CD8 ${ }^{+} \mathrm{PD}^{+}$ lymphocytes exist as targets in the pediatric tumor microenvironment for immunomodulatory therapy. Oncoimmunology 2015; 4: e1029701.

17. Aoki T, Hino M, Koh K, et al. Low frequency of programmed death ligand 1 expression in pediatric cancers. Pediatr Blood Cancer 2016; 63: 1461-1464.

18. Pinto N, Park JR, Murphy E, et al. Patterns of PD1,PD-L1 and PD-L2 expression in pediatric solid tumors. Pediatr Blood Cancer 2017; 64: e26613.

19. Saletta F, Vilain RE, Gupta AK, et al. Programmed Death-Ligand 1 expression in a large cohort of pediatric patients with solid tumor and association with clinicopathologic features in neuroblastoma. JCO Precis Oncol 2017; 1: 1-12.

20. Majzner RG, Simon JS, Grosso JF, et al. Assessment of programmed death-ligand 1 expression and tumor-associated immune cells in pediatric cancer tissues. Cancer 2017; 123: 3807-3815.

21. Dondero A, Pastorino F, Della Chiesa M, et al. PD-L1 expression in metastatic neuroblastoma as an additional mechanism for limiting immune surveillance. Oncoimmunology 2015; 5: e1064578.

22. Altungoz O, Aygun N, Tumer S, Ozer E, Olgun N, Sakizli M. Correlation of modified Shimada classification with MYCN and 1p36 status detected by fluorescence in situ hybridization in neuroblastoma. Cancer Genet Cytogenet 2007; 172: 113-119.

23. Madore J, Vilain RE, Menzies AM, et al. PDL1 expression in melanoma shows marked heterogeneity within and between patients: implications for anti PD-1/PD-L1 clinical trials. Pigment Cell Melanoma Res 2015; 28: 245-253.

24. Taube JM, Klein A, Brahmer JR, et al. Association of PD-1, PD-1 ligands, and other features of the tumor immune microenvironment with response to anti PD-1 therapy. Clin Cancer Res 2014; 20: 5064-5074.

25. McLaughlin J, Han G, Schalper KA, et al. Quantitative assessment of the heterogeneity of PD-L1 expression in non-small-cell lung cancer. JAMA Oncol 2016; 2: 46-54.

26. Watson IR, Takahashi K, Futreal PA, Chin L. Emerging patterns of somatic mutations in cancer. Nat Rev Genet 2013; 14: 703-718. 